\title{
A New Type of Damper and Its Field Tests on Ice-coating Transmission Lines
}

\author{
Wan-li Zhong', Wei Wang ${ }^{1}$, Hang-hang Chen ${ }^{2}$, Wei Luo ${ }^{2}$, Yun-chao Song ${ }^{2}$ \\ ${ }^{1}$ Electric Power Research Institute of Guangdong Power Grid Company, Guangzhou, China \\ ${ }^{2}$ Power and Mechanical Engineering School, Wuhan University, Wuhan, China \\ Email: zhongwanli@163.com,wangwei@gddky.csg.cn, chenhang500@163.com,lw731588184@yeah.net, \\ songyunchao2009@yahoo.cn
}

Received 2013

\begin{abstract}
The paper developed a type of damper with damping additive, of which the field tests were performed on $220 \mathrm{kV}$ transmission line to study its damping effects on vibration of transmission lines. First, based on the common damping measurements, a scheme of filling the damping agent in conventional damper is proposed to suppress the vibration amplitude of the phase/ground line, thus reduce the dynamic stress of the towers and lines and decrease the fatigue damage of the system. Finally, the developed dampers were installed on a $220 \mathrm{kV}$ transmission line in Guangdong Province. The on-line monitoring data show that and the dampers are capable of suppressing the variation of pitch angle and yaw angle of the line, thus verify the effectiveness of the proposed damper.
\end{abstract}

Keywords: Transmission lines ; Damper ; Damping fluid ; Iced transmission line ; Vibration

\section{Introduction}

Transmission line is the key component of the power grid system, thus its structure strength and reliability is important for guarantee the safety of power transmission system. Common disasters of the transmission line system include ice coating, galloping and other types of wind-induced vibration, et. al.

There are generally two type of icing disasters for the transmission line. One is due to the static stress of tower and wires exceeding the allowable stress value, when the ice weights up to several times of that of the wires. In this case, tower collapsing and lines broken may occur. For instance, in early 2008, when the rare snowing and freezing weather occurred in southern region of China, icing disasters leaded to a wide range of power supply interruption [1].

The second type of disaster is galloping of transmission line, which is a type of large amplitude (typically from 0.1 to 1 times of the sag of the span) and low frequency (from $0.10 \mathrm{~Hz}$ up to $3 \mathrm{~Hz}$ ) wind-induced vibration due to wind loads action on an ice-coated or wet snow accretion on the conductors. Comparing to other types of wind-induced vibration of overhead power transmission lines such as Aeolian vibration, turbulent wind-induced buffeting, galloping is the most noticeable and may cause such serious problems as phase-to-phase flashovers due to the short distances between phases, broken conductors, snapping of the line-to-line spacers, damage of insulator chains, and tower bolt failures or even the collapsing of whole tower [2].

Furthermore, there is one more type of harmful phenomenon, sustained small amplitude vibration of the tower-line system. This will cause fatigue damage on the tower and line, which is caused by dynamic stress.

\section{Disaster Prevention Approaches}

There are types of measurements to prevent disaster of icing transmission line, such as thermal de-icing, mechanical de-icing, et. al.

(1) Thermal ice melting method: Using the principle of Joule effect. Improve the conduct temperature through increasing the load current and making short-circuit current, or de-icing with high-frequency high-voltage excitation. In 2001, Joshua D.McCurdy adopted an excitation at approximately $33 \mathrm{kV}, 100 \mathrm{KHz}$ to melt ice [3]. The ice is a lossy dielectric at these frequencies which can be melted.

(2) Mechanical de-icing method: Using mechanical force (manually or automatically). In the early time mechanical de-icing was done by human being. This me- 
thod is simple but with low efficient and insecure. Nowadays the high-tech robot is being developed to replace human being by de-icing, in China, Hunan University develops a de-icing robot, which is an effective way of mechanical de-icing [4] .

(3) Other new technology de-icing method: Many constructive ideas have been proposed, such as applying hydrophobic materials on transmission line, using laser to melt ice[5], et, al.

\section{Damper Structure}

The new damper structure proposed in this paper consists of four parts. A fixed-length high-strength galvanized stranded wire is fixed with iron-casting hammer that has hollow cylindrical shape at both ends, and the hammer is filled with damping agent, while a clamp is used to fix the damper to the phase/ground wire. This structural can be transformed on the base of FR, FD-type damper.

The damping factor varies according to the composition of the damping agent. We adopt different damping agent according the vibration-controlled objectives in different running situation.

The vibration damper is fixed in the transmission line through the clamp. When the transmission line damper vibrates, the damper installed in the transmission line has the upper and lower vibration. The steel strand wire connected to the hammerhead bends up and down because of inertia of the hammerhead. The continuous friction between steel strand wire and damping agent has been reducing the energy, as well as the continuous friction between damping agent and molecule inside the cylindrical hammer. According to the law of conservation of energy, the vibration of the transmission line will be reduced. The greater amplitude of the steel strand wire is, the greater the energy will be damped.

For the vibration of transmission line, the highest point of vibration amplitude is called the crest, while the point stays in the original position is named the node. The distance between two adjacent nodes is called the half-wavelength of the vibration. The damper is usually installed in the crest points that make the biggest swinging amplitude, thus consumes as much energy as possible. Installation distance is determined by the maximum half-wavelength and minimum half-wavelength.

$$
\lambda=\left[\left(\lambda_{\max } / 2\right) *\left(\lambda_{\min } / 2\right)\right] /\left[\left(\lambda_{\max } / 2\right)+\left(\lambda_{\min } / 2\right)\right]
$$

where, $\lambda$ is the damper installation distance(plywood centerline of the clamp centerline to the damper distance); $\lambda_{\text {max }}$ is the maximum half-wavelength of the vibration; $\lambda_{\min }^{\min }$ minimum half-wavelength of the vibration.

\section{Field Application Tests and Data Analysis}

To test the effects of the damper, field tests have been performed on a $220 \mathrm{kV}$ high voltage transmission line system in Shao Guan of Power Grid Company of Guangdong Province. There dampers were fixed along one span of phase line. To comparative evaluate the damping effects, the dampers were only installed on phase C. Based on According to the monitoring and data collection terminal.

Based on the on-line monitoring system of the test line, we collected three parameters, namely the wind yaw angle, pitch angle, and the tension of the line during an icing- deicing cycle from 1st to 10th January in 2012.

Fig. 1, Fig. 2 and Fig. 3 indicate the time curve of the pitch angle, wind yaw angle, and tension. For the test span, the phase $\mathrm{C}$ is installed vibration dampers, while phase $\mathrm{A}$ is not. Compare and analyze the three parameters of phase A and phase $\mathrm{C}$ and make a statistical analysis of tension, pitch angle and wind yaw angle of them, we can draw a conclusion that, after installing the vibration damper, the tension, pitch angle and wind yaw angle are reduced by $72.0 \%, 88.9 \%$, and $2.0 \%$, respectively.

TABle 1. DATA Comparison ANALYSIS OF PHASE A AND PHASE C

\begin{tabular}{|l|l|l|l|}
\hline & Phase A & Phase C & $\begin{array}{l}\text { Relative inhibitory } \\
\text { ratio of phase C rela- } \\
\text { tive to phase A (\%) }\end{array}$ \\
\hline $\begin{array}{l}\text { Max relative change of } 4.3 \\
\text { pitch angle ( }{ }^{\circ} \text { ) }\end{array}$ & 2.5 & $72.0 \%$ \\
\hline $\begin{array}{l}\text { Max relative change of } \\
\text { wind yaw angle }\left({ }^{\circ}\right)\end{array}$ & 0.9 & $88.9 \%$ \\
\hline Max tension (N) & & & $2.0 \%$ \\
\hline
\end{tabular}

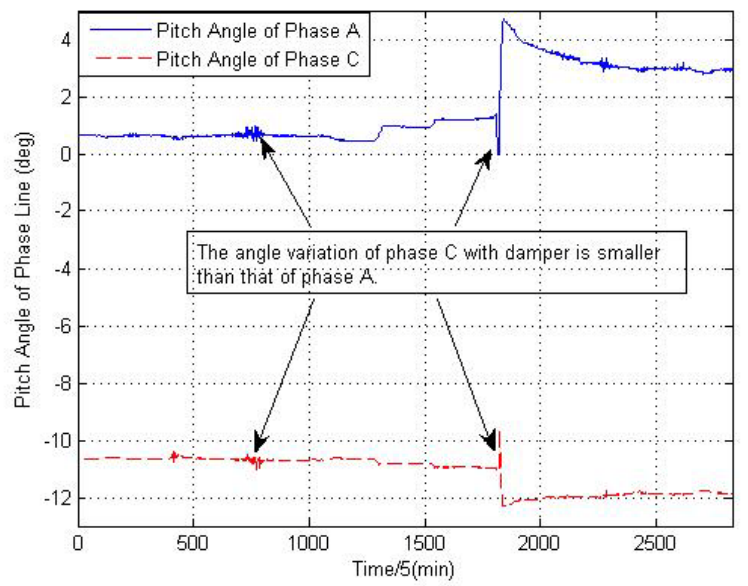

Figure 1. Time history of pitch angle of phase lines A and Phase C 


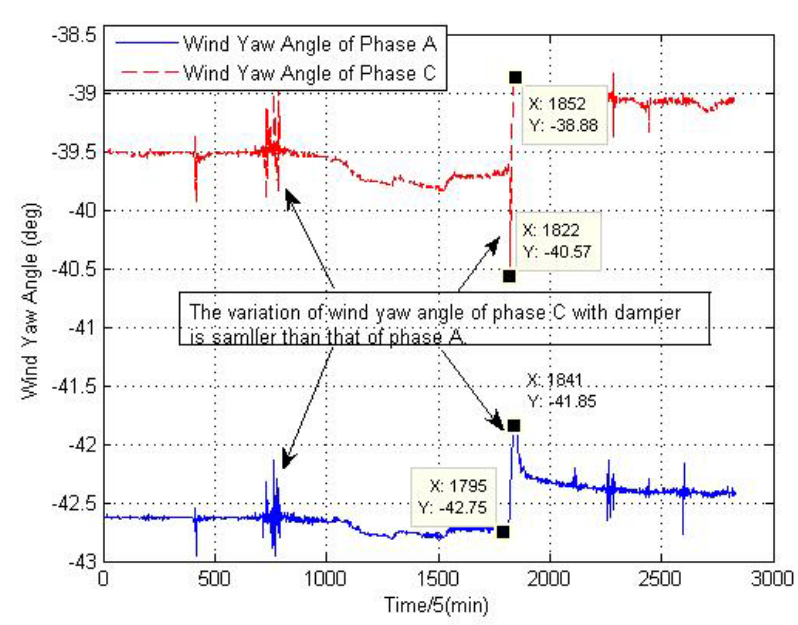

Figure 2. Time history of wind yaw angle of phase lines A and Phase C

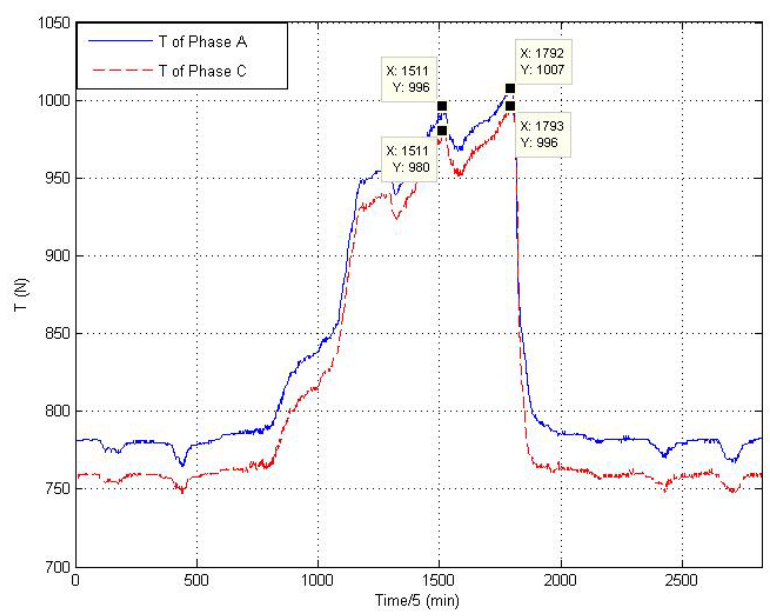

Figure 3.Time history of tension force $\mathrm{T}$ of phase lines A and Phase C

\section{Summary}

Through the field tests of the damper application and collected data analysis, we can conclude that the proposed damper with damp agent is capable of suppressing the vibration of transmission line effectively, thus reduce the fatigue damage, and prolong the system service life. Moreover, this type of damp does not need power supply for it consumes vibration energy passively.

\section{REFERENCES}

[1] X.L Jiang, J. Ma, S.H. Wang, C.X. Sun, L.C. Shu. The Analysis of Transmission Line Ice Damage Accident and the Reasons [J].Electric Power,Vol.11(2005).

[2] Z.G. Lang, L. Liu, B.C Xu. Causes and Countermeasures to Ice Coating Galloping of Transmission Line in Tongliao Area[J]. Northeast Electric Power Technology,Vol.11(2006).pp. 2758-2761.

[3] J.D. McCurdy, C.R. Sullivan, and V.F. Petrenko. Using Dielectric Losses to De-ice Power Transmission Lines with $100 \mathrm{kHz}$ High-voltage Excitation, in Conf. IEEE Industry Applications Society Annual Meeting, Vol. 4, (2001), pp. 2515-2519.

[4] H.X. Zhang, W. Sun, S.Y. Miao. Model Building and Motion Control of Deicing Robot on High Voltage Transmission Line[J].Computer Engineering and Applications, Vol.46 No. 10 (2010)

[5] S.Q. Gu, J.H. Chen, W. Cai, L.J.Qi, X. Zhu. Experimental Analysis and Engineering Designing of Laser De-icing Technology for Transmission Lines. High Voltage Engineering, Vol. 9(2009). 